\section{Trauma Informed Care in Medical Settings: A Pilot Study of Female Patient Perspectives on Coping, Screening and Fostering Resilience}

Sheela Raja ${ }^{1 *}$, Chelsea Rajagopalan², Memoona Hasnain ${ }^{3}$, Tracy Vadakumchery ${ }^{4}$, Alexandra Kupershmidt ${ }^{4}$, Judy Hamad ${ }^{4}$ and Michelle Hoersch ${ }^{5}$

\begin{abstract}
Traumatic events such as sexual assault, interpersonal violence and community violence are common in the United States population and are often associated with negative health effects. Many healthcare settings have attempted to implement trauma informed care initiatives to better meet the needs of female trauma survivors. We conducted a pilot study involving in-depth qualitative interviews with eighteen women to gain an understanding of how patients in a large, urban environment believe trauma informed care should be provided in healthcare settings. We were particularly focused on how women connected their trauma history to subsequent health issues and how they felt the healthcare system could be responsive to the needs of survivors. These insights can ultimately be used to provide recommendations for improving trauma-informed initiatives in the healthcare system.
\end{abstract}

\section{Keywords}

Trauma; Coping; Screening; Resilience; Patient; Pilot

\section{Introduction}

\section{The prevalence of trauma}

Exposure to traumatic events is common in the United States population. These events include sexual assault, interpersonal violence, community violence, and combat. In large-scale studies that are representative of the U.S. population, $22 \%$ of women have reported a history of sexual assault as adults [1], 17\% percent of women report a history of childhood sexual abuse [2], and as many as $20 \%$ of women report being physically assaulted by an intimate partner in their lifetime [3]. In addition, exposure to community violence (e.g., robbery, physical assault, gun violence) is also common in U.S. neighborhoods with high levels of poverty, unemployment, family disruption, and low levels of social cohesion [4,5]. Overall, there are gender differences in the types of trauma that men and women may experience. Women are more likely to experience

${ }^{*}$ Corresponding author: Sheela Raja, PhD, UIC College of Dentistry, 801 S. Paulina St, M/C 850, Chicago, IL 60612, USA, Tel: 312413 0559; E-mail: sraja1@uic.edu

Received: September 18, 2014 Accepted: April 10, 2015 Published: April 14, 2015 interpersonal trauma (domestic violence, sexual assault, childhood sexual abuse) and men are more likely to be exposed to combat [6].

\section{Health effects of trauma}

Following a traumatic event, survivors may experience emotional consequences such as fear, social isolation, difficulty trusting others and sleep disturbances. These symptoms may eventually lead to the development of major depressive disorder, post-traumatic-stress, dissociative issues, and other anxiety disorders [7,8]. Survivors may also engage in behaviors that help them "cope" with traumatic memories, but have negative health consequences, including smoking cigarettes, drinking alcohol, using illicit and prescription drugs, engaging in unprotected sex, or overeating to manage their emotional distress [8]. Although these behaviors may provide short-term improvements in mood, they have long-term negative consequences on overall health $[9,10]$. For example, child abuse has been linked to subsequent alcohol and drug use [11], and interpersonal violence has been associated with increased chronic pain, gastrointestinal problems, gynecological, and cardiac issues [12]. There is also a wellestablished body of research focused on the association between sexual violence, negative ways of coping (e.g, substance abuse), increased sexual risk behavior [13,14] and HIV infection [15]. Trauma exposure has been associated with arthritis/rheumatism, back/neck pain, headaches, chronic pain, heart disease, and ulcers, and exposure to multiple traumatic events results in an increased disease burden $[10,16]$. Living in a violent community (e.g., one with frequent gun violence, assault, robbery, etc.) also influences health. Residents of these neighborhoods may have fewer opportunities for outdoor exercise, and they may also experience chronic levels of physiological arousal because of stress. Compared to other areas, residents of poor, high-crime communities report more chronic health conditions, such as cardiovascular disease and diabetes [17]. Community violence has been studied in men, but there is also a growing understanding that experiencing and witnessing community violence negatively impacts adult women's health coping behaviors [18-20].

In addition to behavioral coping methods, the link between trauma and disease outcomes is also influenced by neurobiology. During chronic stress reactions, particularly in patients with posttraumatic stress disorder, the Sympathetic Nervous System (SNS) and Hypothalamus-Pituitary-Adrenal (HPA) axis become chronically activated, causing chronic increases in blood pressure and blood sugar and resulting in damaged blood vessels, heart disease and insulin resistance [21]. Overall, post-traumatic stress may increase vulnerability to inflammatory or autoimmune disorders [21]. Compared to men, women who are exposed to traumatic events are more likely to develop post-traumatic stress disorder, suggesting that it is important to provide traumatized women with the appropriate support and resources to reduce the mental and physical health burden of trauma [22].

\section{Trauma-informed care in health settings}

Although negative coping behaviors contribute to higher levels of health problems and high levels of overall healthcare utilization for illness [23], trauma survivors may actually avoid seeking preventive medical care, such as mammograms, cervical cancer screenings, and 
even dental prophylaxis [24-27]. A trauma history may also influence medication adherence [28]. Trauma survivors may fear that taking medication will result in a loss of psychological or physical control or they may worry that certain medications will make them feel emotionally numb. Medication adherence also requires thinking about the one's physical body; some trauma survivors' primary coping mechanism is avoidance of bodily sensations and awareness [29]. When they do seek care, patients often experience specific physiological reactions when trauma memories are "retriggered" $[8,30]$. Many healthcare visits involve the provider being in close proximity to the patient and needing to touch the patient's body. For some traumatized patients, this may be particularly retriggering depending on the nature of their past trauma. In response to the needs of survivors, recent efforts have been made to implement "trauma-informed care" (TIC) in various human services settings, including social service, education, healthcare, and corrections. The basic definition of TIC is when every part of service is assessed and potentially modified to include a basic understanding of how trauma impacts the life of an individual seeking services [31].

\section{Unanswered Questions: Patient Perspectives on} Trauma-Informed Healthcare

\section{Patient experiences in the healthcare system}

Female survivors of traumatic events report varied experiences within the healthcare system. These experiences may have serious consequences-both in terms of treatment compliance and engagement in preventive care. When providers are empathic and sensitive, survivors may be more likely to follow up on appointments and engage in preventive care [32]. Similarly, trauma survivors have reported that they establish better rapport with healthcare providers who are empathic, provide referrals, and allow them some control over their appointments [33]. However, when survivors are treated negatively or insensitively by the medical system they may feel "revictimized" or "secondarily victimized," leaving them less likely to seek help from the healthcare system in the future [3436]. In the healthcare system, "secondary victimization" may occur when providers focus exclusively on biomedical concerns without appropriate empathy, or when victims feel judged or shamed when discussing their coping mechanisms (e.g., smoking, overeating, etc.). Therefore, another essential component of developing traumainformed healthcare involves understanding how survivors of trauma have experienced the healthcare system, and how the system can be modified to better meet their needs [31].

\section{Patient perspectives on routine screening}

Very few studies have examined whether female patients would like healthcare providers to screen for a history of trauma on a routine basis. In one study, a majority of patients were in favor of screening for physical and sexual abuse, however, a majority of physicians reported they did not screen for these issues at initial or annual visits [37]. Another study found that among childhood sexual abuse survivors, some women favored routine screening, while others found it invasive [33]. In a study of survivors of childhood sexual abuse, participants suggested that providers should ask what can be done to make patients more comfortable, but that screening directly for abuse may not be appropriate in all cases [38]. Clearly, there is a need to understand the preferences of survivors of various types of traumatic events (not limited to childhood sexual abuse) related to routine trauma screening.

\section{Patient perspectives on trauma and coping}

Cross-sectional and longitudinal surveys on trauma and health are extremely important; however, another essential component of improving the implementation and delivery of TIC involves understanding and including the voices of female trauma survivors. Therefore, it is important for research to focus on how survivors understand the links between their own trauma history, coping style, and their physical health.

The goal of this pilot study was to gain an in-depth understanding of how female patients in a large, urban environment believe TIC should be provided in healthcare settings. We were particularly focused on how women connected their trauma history to subsequent health issues and how they felt the healthcare system could be responsive to the needs of survivors. These insights can ultimately be used to provide recommendations for creating trauma-informed initiatives in the healthcare system.

\section{Methods}

\section{Ethics statement}

This project was approved by the University of [deleted to ensure blind review] Institutional Review Board (IRB). Participants signed an informed consent form advising them of their rights. Participants were advised of the following: 1) they could stop the interview at any time or refuse to answer any question without penalty, 2) their participation would not influence their ability to receive healthcare at the University clinics, 3) all interviews were confidential, and 4) interviews would be audiotaped and transcribed without any identifying information.

\section{Study setting and patient population}

The University of Illinois at Chicago Health Sciences campus is located on the near west side of Chicago. The campus clinics serve patients who are largely uninsured or underinsured. Sixty-five percent of the Family Medicine patient population is female and $35 \%$ are male. Many patients are underserved ethnic minorities, with a patient population that is approximately $10 \%$ Hispanic and 34\% African American. The dental clinics, also located on the health sciences campus, serve a patient population that is approximately 25\% Hispanic and 25\% African American.

\section{Participants and interview}

Eighteen women were recruited using two methods: 1) As part of a larger self-report survey examining experiences in the healthcare system and history of traumatic events, patients in the waiting room at the University of [deleted to ensure blind review] dental and family medicine outpatient clinics were given an optional locator form to complete if they were interested in being contacted to participate in an in-depth interview in the future. 2) IRB approved fliers were posted around the medical campus to invite patients to participate in an interview to discuss their experiences in the healthcare system. The fliers indicated that researchers were trying to learn more about how various people experience the healthcare system, and how medical providers should be trained on various topics, including traumatic events and communication skills. Patients who were interested contacted our study staff. 
Ninety eight participants completed optional locator forms or called expressing interest in the study (20 males and 78 females). Patients were screened by phone to determine their eligibility. Patients needed to be at least 18 years of age, able to communicate in English, and have 30-60 minutes available to complete the oneone one interview during scheduled clinic hours. A history of trauma was not required for participation and no trauma screening was completed via telephone. During the phone screen, twenty-two participants ( 18 women and 4 men) reported they were not interested in the interview. Over a 4-month time frame, we scheduled interviews based the mutual convenience of the interviewer and the participant. Based on the guidelines suggested by Kvale [39] for conducting qualitative interview studies, our target sample size was between fifteen and twenty patients to achieve data saturation. Patients who attempted to schedule interviews after we reached data saturation were told that the study was no longer enrolling new participants. We interviewed 18 women and 3 men. For the purpose of this analysis, we only included the women in our sample.

All interviews took place in a private office with the principal investigator (PI), a licensed clinical psychologist with training in health psychology. Interviews took approximately 45 minutes to one hour to complete. Participants received a $\$ 20$ grocery store gift card to compensate them for their time. The interview itself was semi-structured. Participants understood that this was not a therapy session and there would not be any follow up appointments. Openended questions focused on what type of setting participants obtained their healthcare and if they visited a physician regularly. Participants were asked to reflect on their most positive or negative healthcare visits. A portion of the interview was focused on the experience of difficult or stressful life events. The interviewer asked the participant, "Have you ever experienced anything you would consider traumatic? Something life-threatening and extremely stressful like a natural disaster, a car accident, an assault?" The interviewer did not probe for details about the traumatic events, and participants were free to elaborate as little or as much as they preferred. Because the purpose of the interview was not to diagnose psychological impairment, the interview did not include structured clinical questionnaires or other diagnostic questions. If participants reported a traumatic event, the interviewer asked, "Do you think this influences how you take care of yourself physically? Do you think it influences you going to the doctor or dentist?" Participants were also asked about whether or not they thought that healthcare providers should screen for a history of traumatic events as part of routine practice. After the interview was completed, all participants were provided with a referral sheet listing local mental health services and hotlines for domestic violence, sexual assault, and crime victimization. None of the participants reported experiencing significant distress during the interview.

\section{Analysis}

The research team consisted of the principal investigator and four research assistants. We analyzed the interviews using content analysis, as outlined in Hancock [40]. The coding scheme was created using an iterative process. The PI and research assistants read through 3-5 transcripts each and made notes about general themes that emerged in these interviews. The team then met to create an initial coding scheme. Each team member individually read through another five transcripts to add to and refine the coding scheme. Based on group discussion, and eventually group consensus, the coding scheme was divided into major and minor categories.
The data was entered into Atlas.ti for formal coding. Over the course of several months, each research assistant coded four to five interviews. Then research assistants examined three to five transcripts that were initially coded by another team member, allowing for each transcript to be analyzed by two team members. Discrepancies that arose in coding were discussed in team meetings and resolved by group discussion. Finally, we examined the final categories for larger phenomena [41]. Overall, we used both deductive and inductive methods in our analysis [42]. The semi-structured interview questions were based on a prior knowledge of traumatic events and health; however, the specific categories and larger phenomena that emerged from these interviews followed from an inductive process.

\section{Results \\ Demographics}

Table 1 provides demographic information about the participants as well as information about trauma history. Because of our recruitment approach-recruiting at University outpatient clinics as well as posting fliers-participants received care at the University clinics as well as at other local hospitals and outpatient settings. Although our eligibility criteria did not require a history of traumatic events, it is interesting that most of our participants were trauma survivors who were quite candid about their experiences. Participants discussed domestic violence as adults and children, physical and sexual abuse during childhood, and violent crime/community violence. Participants also discussed caregiving responsibilities, the sudden death of loved ones, as well as car accidents.

Physical and sexual violence as well the living in violent communities appeared to take the greatest toll or participants. Figure 1 illustrates themes that emerged during our interviews. For example, one participant talked about being sexually assaulted as a teenager.

[After my assault happened] I'm running around the street naked, knocking on doors, like, "Can I please get some clothes, please?" And no one likes to get involved... They shun you off, don't want to help, don't want to call the police, don't want to let you in their home ... It was nerve-wracking because I had to go through all these series of tests and everything [at the emergency room]... And then, sometimes they never find the person or the right person. You're just holding on to all this information and a rape kit. (31 year old, African American female).

Table 1: Demographic Characteristics of Study Participants.

\begin{tabular}{|c|c|}
\hline Participant Characteristic $(n=18)$ & \\
\hline Age (average) & $\begin{array}{l}45 \text { years }(S D=13.5 ; \\
\text { Range } 21-65 \text { years) }\end{array}$ \\
\hline $\begin{array}{r}\text { Race/ethnicity: White/Caucasian } \\
\text { African American } \\
\text { Hispanic }\end{array}$ & $\begin{array}{l}56 \% \\
28 \% \\
16 \%\end{array}$ \\
\hline $\begin{array}{r}\text { Reported Trauma History: Yes } \\
\text { No }\end{array}$ & $\begin{array}{l}78 \% \\
33 \%\end{array}$ \\
\hline $\begin{array}{l}\text { Type of Trauma (among those who reported trauma } \\
\text { history)*: } \\
\text { Living in a violent neighborhood (witnessing gunshots } \\
\text { and crime): } \\
\text { Victim of violent crime (robbery, mugging): } \\
\text { Experienced domestic violence as an adult: } \\
\text { Witnessed domestic violence as a child: } \\
\text { Experienced sexual assault/abuse as an adult: } \\
\text { Experienced sexual assault/abuse as a child: } \\
\text { Car accident: } \\
\text { Sudden death of loved one: }\end{array}$ & $\begin{array}{c}22 \% \\
14 \% \\
14 \% \\
7 \% \\
14 \% \\
14 \% \\
14 \% \\
7 \%\end{array}$ \\
\hline
\end{tabular}

*Participants could discuss more than one traumatic event, so percentages do not total 100 


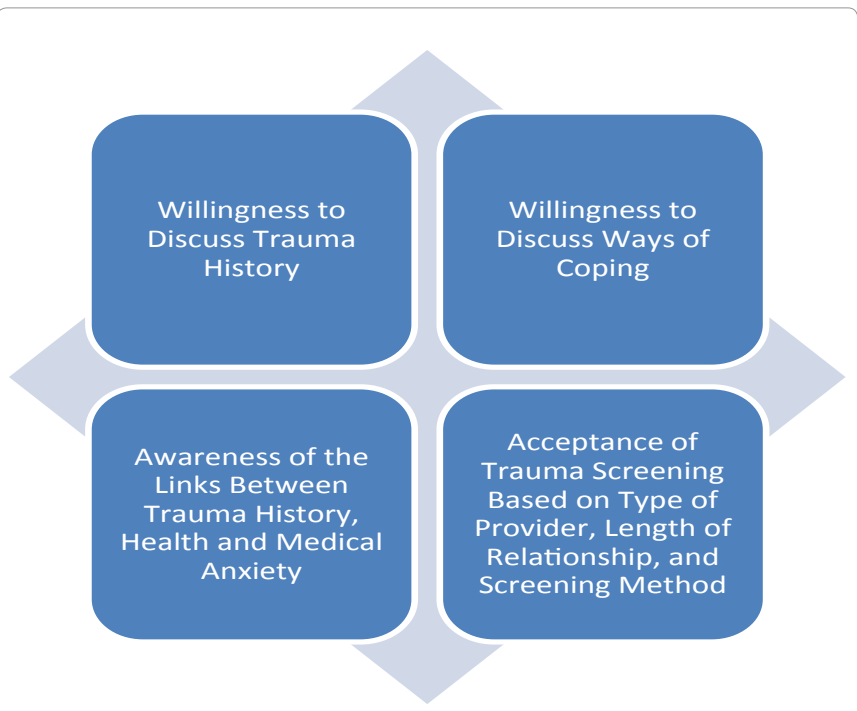

Figure 1: Emergent Themes Reported by Participants. child.

Another participant discussed witnessing domestic violence as a

I grew up in a very like violent home. My dad was always, hitting my mother...He would drink. He wasn't an alcoholic... when he'd get drunk he would be very aggressive... My dad broke her nose one time. And I do remember when he broke her jaw (39 year old, Hispanic female).

Another participant talked about her experiences in multiple foster homes.

I was a ward of the State... The whole thing [was traumatic] because I was in so many of them, in a lot of them... A lot of neglect and a lot of prejudice and a lot of sexual abuse... Everything. The whole nine yards (55 year old, Hispanic female).

Several participants described living in violent neighborhoods, with frequent street crime or gun violence. Because these incidents are ongoing, they contribute to a chronic level of stress.

Maybe two, three weeks ago, I was coming from the laundry mat and right across... they was shooting. And I seen them so I run in the alley... and I called the police... When I get off of work at night it's 11:00 at night... You be scared a couple days... But this is where I stay. If peoples would speak up and take a stand. Now it ain't like I ran over there and stopped them from shooting, but I did call the police. A lot of folks don't even do that. You know, you just can't, you know, let stuff like that stop you from living (50 year old, African American female).

\section{Trauma, coping, health and medical anxiety}

Overall, women in our sample had a great awareness of how they coped with trauma (both positively and negatively) and how this coping might influence their health and healthcare utilization (Figure 1). Several women mentioned professional support and others discussed using social support and spirituality to heal.

I've been in group sessions. I've had therapy for this and everything...It helps to talk about it and talk to other people about it who understands and who is going to listen...And I go to church a
lot...I've learned, I've been taught to forgive your enemies. Something that is hard to do (31 year old, African American female, survivor of childhood sexual assault).

Six participants mentioned dealing with feelings of anxiety. Anxiety was present immediately after stressful life events; for some participants, it was a long-term symptom. Overall, anxiety was mentioned far more than any other psychological symptom.

I'm very cautious everywhere I go. If I know that there's something that's like off about a person, I try to avoid them as much as possible or I try to get out of the situation...And sometimes I do have trouble sleeping at night... I'm always worried that someone is going to break in... It's really hard to wake up in the morning if you're laying there until like 1:00 and you think you hear something or you're worried that someone might walk in or something like that (21 year old, White female, survivor of attempted break-in).

In my area, the way they cope with it [constant violence] is they don't come outside... We used to sit on the porch... Now... I don't hear anybody on the back porch anymore. You know, walk our dogs. And you might stand there and chat a little bit. I don't see them do that no more...I'm not going to let them just take over. I need to go to work. I have to go grocery shopping... What happened happens, and I pray for the best (50 year old, African American female, lives in a violent neighborhood).

We asked participants if they believed these difficult or stressful life events influenced their health habits or health status. Interestingly, only two participants spontaneously discussed healthy coping methods.

Well, I sometimes do like breathing exercises. I like to distract a lot (41 year old, White female, history of homelessness).

Just giving yourself rest. I think that's the big thing, getting enough sleep, even though you're stressed out...I sleep a lot, like nine hours a night, which I think is important. (26 year old, White female, survivor of domestic violence);

A majority of participants mentioned less adaptive ways of coping with traumatic events, including overeating, smoking, and substance abuse. Participants were very insightful in identifying their coping mechanisms.

I'm an only child so I was cooking for myself all the time. [I was] eating more than I should at times though I eat a lot. But I was eating more than that...compiling stuff....Eating out of the pots and pans. I was getting ridiculous with it (31 year old, African American female, survivor of childhood sexual assault).

I did hear the other day, I was just going through my e-mail, "Oh, another kid has been shot right by Obama's house." I'm sure I probably got a piece of chocolate or something, I reacted in some way to that... I remember closing the e-mail "I don't want to hear about it" Those kinds of things, probably raised my blood pressure even higher (59 year old, African American female, lives in violent neighborhood).

Definitely I got a lot thinner. And then also I was self-harming at the time too so I had like cuts, you know... I think that I was, at the time, abusing a lot of substances and being like a mess in that way... Everyone I knew who did drugs did them because they were numbing out of whatever they were going through. (26 year old, White female, survivor of domestic violence).

Most participants were able to succinctly summarize the 
relationship between stress, coping, and traumatic and stressful life events in their own lives.

I smoke about a pack a day... I think if you're emotionally distressed, you become physically ill. I think if you become physically ill, you become emotionally distressed. I think the two just go along. Just like eating. You eat a lot, you get fat. You don't eat so much, you lose weight. They go hand-in-hand. It's a yin and a yang (68 year old, White female, experienced multiple illnesses and deaths of family members).

It's like you get the people in Syria. After you see so much killing, so much destruction, it becomes to be normal. When it doesn't happen, it's a happy day. And you're like joyful because it didn't happen. But you don't expect that to happen all the time. You understand?... With me growing up, the normal to me was for something always to happen. So then when something did good happened, I would just wait until it would mess up because it never stayed. ... It's like I blocked all this stuff out of my head... I smoked...it was the bad for me because I was already was asthmatic. You know, so that took a toll all by itself, you know (55 year old, Hispanic female, survivor of childhood physical and sexual abuse).

It's less exercise. You're not exercising. That's good for your health. Everybody need to talk to someone else every now and then, that's good for you. It's like you almost locked up. You know, you can't come and go. You can't stand here. You know, you're scared they're going to shoot so you just stay in your house, maybe look out the window. Now you're sitting up on a TV or laying down, that ain't good for you (50 year old, African American female, lives in a violent neighborhood).

Six participants felt that their post-trauma anxiety also contributed to feelings of medical anxiety and distrust of healthcare providers.

Someone had control over your body in a really harmful or damaging way... Giving that over to someone else in a different capacity is really frightening because vulnerability has only been connected with pain... Doctors just have a lot of responsibility to be aware of that position that they're in... I want them to know that they [survivors of trauma] are more sensitive about, you know, their bodies and things that have happened. ...I've had like certain physical things that I have not ever gotten addressed because, in my head, they remind me of abuse... For instance, I hurt my back. And in my mind...it reminds me of him and like what happened with him. And so even though I had a couple of doctors tell me like, "You should get an X-ray. You should get this looked at," I just never would. I just wouldn't do it (26 year old, White female, survivor of domestic violence).

A few participants expressed fear of potential diagnosis and lack of engagement in preventive care.

So I'm the type of person that I was going to the doctor a lot, but it seemed like the more I went the more I started finding out more and more that was wrong with me. So I kind of capped it...I mean, it's like now I don't even want to know what else is wrong with me (55 year old, Hispanic female, survivor of childhood physical and sexual abuse).

\section{Assessment and screening}

We asked all 18 participants whether they thought healthcare providers should be screening patients for trauma on a routine basis. Although four women did not report a personal history of stressful or traumatic events, all of these women still had opinions on how healthcare providers could approach this topic (Figure 1). As such, we retained those four interviews in our analysis of this theme. We asked women how much they think their providers should know about a history of traumatic or stressful life events. Overall, eleven participants strongly believed that all healthcare providers should be routinely asking patients about trauma history. Several participants felt that screening should be brief, while others felt that asking about trauma history in-depth may help deepen the relationship between the patient and her provider.

These things should be asked then you'll know how to handle that person...You know, "your personal business but I just would like to know, you don't have to tell me too much details. Has it happened to you, yes or no?" Then, you know, "was it very hard for you?" Just make it a yes or no answer then they won't feel... "Why do you want to know that for?" (31 year old, African American female, survivor of childhood sexual assault).

I think that asking about your environment is very relevant because those are, I would say those are silent stressors. There are a lot of stressors that I've learned to live with, but that still have me in a state of stress, and so I, I would hope that a doctor would be curious about that (59 year old, African American female, lives in violent neighborhood).

I think it would help out a lot actually, if they maybe made like a survey or like a confidential... survey to see if, you know, traumatic events really do affect a person like that. So I feel like a questionnaire would be helpful because a doctor obviously would know right away. He would have a conversation to the patient about it... I think it is important for doctors to get as deep as they can, like in terms of knowing about their past (21 year old, White female, survivor of attempted break-in).

I've always thought that the history is really important. It might not turn out being important on that day, you know, or that episode of being taken care of for some reason. But it gives you insight into the patient and why they might be acting the way they're acting or, you know, typical things that they might be concerned of or why they might be hyper-vigilant about certain things, you know (47 year old, White female, kidnapped by a stranger as a child).

After the bruises have healed and the cuts and scrapes have healed there is a lot of emotional trauma that goes undiagnosed, so to speak.... I know doctors are so busy they might not necessarily have time to sit down with each patient and divulge personal aspects of their patient's lives but I think you could easily start initiating the conversation through paper and a questionnaire and that might be a starting point to begin the communication. Sometimes people are more comfortable putting it on paper (52 year old, White female, survivor of emotionally abusive relationship).

A minority of participants underscored that providers do not need to ask specifically about abuse history. Instead, they stressed an increased awareness of the issue overall and general conversations might positively influence patient-provider relationships.

Basically to assume pretty much that any patient you come in contact with might have like any history, you know. I mean, I don't think I look like particularly super put together...but I'm dressed fine... You wouldn't necessarily looking at me know my full history... You can't really know that someone has experienced like 
pretty horrific things if you don't consider it...You don't even have to say the word or ask them directly, but just to have in your mind that this person could be a survivor ... If they seem hesitant, they don't want to do something [medically], or it's hard getting them to do whatever you need them to do, or it's an uncomfortable experience, whatever, just to know that they might not be doing that because they are being difficult or they're being lazy or stupid or whatever... But just to maybe ask yourself, "Well, like is there a reason...why this might be so frightening..." And you also don't want to necessarily like open up a can of worms then the doctor is sitting there having someone sobbing for two hours (26 year old, White female, survivor of domestic violence).

One participant felt strongly that overly personal questions are a violation of privacy and providers should wait until patients feel comfortable raising the topic themselves.

If it's not going to affect my medical care, I don't care about your demographics. You know, I'm not trying to be rude. I'm allowed confidentiality... If they force it, if they ask again and again, if they're harsh and cold or demanding or intolerant or impatient, you're automatically going to put the wall up again and you will never get the answer you want. We're going to the central medical records, right So they're going to have all the information everywhere (41 year old, White female, history of homelessness).

Overall, participants were unsure about how deeply healthcare providers should delve into the topic of trauma. There were some differences based on the specialty of the provider and the length of the patient-provider relationship. Participants also made recommendations for self-report, questionnaire based screening, particularly when there was not an established, long-term relationship with the patient.

I think if you don't have a good relationship with your doctor you probably wouldn't share any of that to begin with, especially on those surveys they make you fill out... I probably wouldn't go into anything with a doctor I don't know. Unless I had been seeing them for a while or I felt really comfortable with them (26 year old, White female, survivor of domestic violence).

The line of questioning has to somehow lead up to that. I just think that it has to somehow be relevant. But if I just come in and say that something hurts and then the doctor says, "Well, is it domestic violence?" then I think I'd be offended, yeah (36 year old, African American female, survivor of serious car accident and Ku Klux Klan violence as a child).

I think a primary care physician, if they're going to go through a checklist of things, yeah, I think it should be on there because every year I have to update my, whatever you want to call it, profile... I'm talking about primary care physicians. Specialists don't have the time. They're not getting reimbursed. This is about money and medical reimbursement. [But] I think if a doctor misses it at the beginning it's hard to introduce it [the topic of trauma] without appearing, you know, it kind of appears too contrived (65 year old, White female, no reported trauma history).

This participant also summarized the pros and cons of standardized trauma assessment questions. I think anybody who is used to answering standardized questions, you're kind of inviting them to reveal and to shut down at the same time, and the way it's written in these standardized things. "Is there something that you feel that you would, if you have liked, been able to express? Something that happened in your life you would like to have it able to express to a professional if the setting had been right or you had been comfortable?" Let them check that off and then you follow up on that... It could be worded in a way that's interested and gentle, and would lead the patient to open it up. They could check no, but they could park it at the back of their head like, "That's been asked..." And then at a later time, they might say, "You know what, yeah, I pushed it to the back of my head because I thought, well, who the hell am I going to talk about this." I think just to let people know there's a possibility. You know, there might be somebody out there for you, and I [the healthcare provider] might be your first line... [your] first responder (65 year old, White female, no reported trauma history).

\section{Discussion}

As the field of trauma-informed healthcare is emerging, including the voices of female survivors is an essential component in structuring successful programs. Although this was a pilot study with a small sample size, our in-depth interviews with women suggested several important variables that should be further explored when designing TIC interventions in healthcare settings. Firstly, women in this sample reported extremely varied experiences of trauma, including domestic violence, sexual assault, and community violence. In addition, many participants spoke of care-giving burdens, family illness, and motor vehicle accidents. When screening for potentially traumatic events, it is important for TIC programs and providers to consider the wide array of experiences that female patients may have been confronted with in the past.

Our pilot interviews also pointed to the importance of allowing patients enough time to discuss how their health related coping could be related to a history of stressful events. Interestingly, some participants reported they had never been asked about how their current health behavior was related to prior life experiences. When participants were given the opportunity to reflect, they were able to draw distinct links between their trauma histories, coping methods, and health status. Women discussed overeating, smoking, substance abuse, lack of exercise, insomnia, and self-harm. This finding supports the importance of training healthcare providers on how trauma influences health behavior and health outcomes. To be trauma-informed, providers must learn to discuss maladaptive coping methods (e.g., overeating, smoking) in a compassionate, non-judgmental manner [43]. On a related note, some participants discussed how medical anxiety may relate to a trauma history. Anxiety may be related to specific procedures and fear of being touched, or it may relate to receiving a difficult diagnosis. It is possible that some survivors may have a sense of foreshortened future, believing that they will not have a normal life span. Again, the narratives of female trauma survivors suggest that TIC programs should include education about the various manifestations of medical anxiety in trauma survivors. Sensitive care should include specific communication strategies for providers to engage patients who may be experiencing medical anxiety secondary to trauma $[30,31]$.

Finally, participants had important insights into the role of screening in TIC. Most women were supportive of routine screening by all healthcare providers. Many felt that when questions were asked on paper and then followed up on during a clinical interview, survivors would be likely to disclose and receive the services they needed. Other participants suggested that providers may want to wait until the patient discloses a trauma history on their own, thus respecting a survivor's right to privacy and confidentiality. One participant 
Citation: Raja S, Rajagopalan C, Hasnain M, Vadakumchery T, Kupershmidt A, et al. (2015) Trauma Informed Care in Medical Settings: A Pilot Study of Female Patient Perspectives on Coping, Screening and Fostering Resilience. J Womens Health, Issues Care 4:3.

brought up important considerations about the use of information, including storage of a patient's history on a universal, electronic medical record. Overall, while many of the women interviewed were supportive of routine screening, there was not a consensus on the best method of delivery (in a clinical interview versus written) or the optimal setting (all providers versus primary care providers). This finding was consistent with other works [39], suggesting that implementing routine trauma screening in healthcare requires further study. It will be essential to include patient perspectives on this issue, both in future in-depth, qualitative interviews and in largescale surveys focused on trauma screening preferences.

Overall, in-depth interviews with eighteen women yielded important insights into the ways TIC can be initiated and refined in healthcare settings. Women with heterogeneous trauma histories, and of varying ages and ethnicities reported many similar themes. When given an opportunity to examine their coping strategies, they all felt trauma influenced their health in important ways and they had specific suggestions for how providers could engage them in care. This pilot also had limitations. Our sample was all female and women overwhelmingly responded to our recruitment methods. While it is possible that our interview specifically interested trauma survivors and perhaps more women in our clinic had trauma histories, it may also be possible that men were not comfortable with the individual, face to face interview format. To include a broad array of trauma survivors, it is important for future work on patient perceptions of trauma informed care to use varied methodology (e.g., in depthinterviews, paper and pencil surveys, online surveys and focus groups) in diverse settings (e.g., medical, and mental health, as well as larger community-based surveys). It is essential that future work continue to include the voices of survivors as trauma-informed interventions in healthcare are developed and implemented.

\section{Acknowledgements}

The authors would like to gratefully acknowledge the Research Open Access Publishing (ROAAP) Fund of the University of Illinois at Chicago for financial support towards the open access publishing fee for this article.

\section{References}

1. Elliott DM, Mok DS, Briere J (2004) Adult sexual assault: prevalence, symptomatology, and sex differences in the general population. J Trauma Stress 17: 203-211.

2. Putnam FW (2003) Ten-year research update review: child sexual abuse. $J$ Am Acad Child Adolesc Psychiatry 42: 269-278.

3. Tjaden $P$, Thoennes $N(2000)$ Full report of the prevalence, incidence, and consequences of violence against women: Findings from the national violence against women survey. U.S. Department of Justice, Washington, DC.

4. Hipp JR (2010) A dynamic view of neighborhoods: The reciprocal relationship between crime and neighborhood structural characteristics. Social Problems 57: $205-230$

5. United States Department of Justice, Federal Bureau of Investigation (2012) National Incident-Based Reporting System, 2012.

6. Perkonigg A, Kessler RC, Storz S, Wittchen HU (2000) Traumatic events and post-traumatic stress disorder in the community: prevalence, risk factors and comorbidity. Acta Psychiatr Scand 101: 46-59.

7. Kimerling R, Ouimette P, Wolfe J (2002) Gender and PTSD. Guilford Press.

8. Raja S (2012) Overcoming trauma and PTSD: A workbook integrating skills from ACT, DBT, and CBT. New Harbinger Publications.

9. Banyard VL, Edwards VJ, Kendall-Tackett K (2008) Trauma and physical health: Understanding the effects of extreme stress and of psychological harm. Taylor \& Francis, USA.
10. Felitti MD, Vincent J, Anda MD, Robert F, Nordenberg, MD, et al. (1998) Relationship of childhood abuse and household dysfunction to many of the leading causes of death in adults. Am J Prev Med 14: 245-258.

11. Herrenkohl T, Hong S, Klika JB, Herrenkohl RC, Russo MJ (2013) Developmental Impacts of Child Abuse and Neglect Related to Adult Mental Health, Substance Use, and Physical Health. J Fam Violence 28.

12. Campbell JC (2002) Health consequences of intimate partner violence. Lancet 359: 1331-1336.

13. Lloyd S, Operario D (2012) HIV risk among men who have sex with men who have experienced childhood sexual abuse: systematic review and metaanalysis. AIDS Educ Prev 24: 228-241.

14. Meyer JP, Springer SA, Altice FL (2011) Substance abuse, violence, and HIV in women: a literature review of the syndemic. J Womens Health (Larchmt) 20: $991-1006$.

15. Logan TK, Cole J, Leukefeld C (2002) Women, sex, and HIV: social and contextual factors, meta-analysis of published interventions, and implications for practice and research. Psychol Bull 128: 851-885.

16. Sledjeski EM, Speisman B, Dierker LC (2008) Does number of lifetime traumas explain the relationship between PTSD and chronic medical conditions? Answers from the National Comorbidity Survey-Replication (NCS-R). J Behav Med 31: 341-349.

17. Ross CE, Mirowsky J (2001) Neighborhood disadvantage, disorder, and health. J Health Soc Behav 42: 258-276.

18. Taylor L, Zuckerman B, Harik V, Groves BM (1994) Witnessing violence by young children and their mothers. J Dev Behav Pediatr 15: 120-123.

19. Clark C, Ryan L, Kawachi I, Canner MJ, Berkman L, et al. (2008) Witnessing community violence in residential neighborhoods: a mental health hazard for urban women. J Urban Health 85: 22-38.

20. Johnson SL, Solomon BS, Shields WC, McDonald EM, McKenzie LB, et al. (2009) Neighborhood violence and its association with mothers' health: assessing the relative importance of perceived safety and exposure to violence. J Urban Health 86: 538-550.

21. Pace TW, Heim CM (2011) A short review on the psychoneuroimmunology of posttraumatic stress disorder: from risk factors to medical comorbidities. Brain Behav Immun 25: 6-13.

22. Stein MB, Walker JR, Forde DR (2000) Gender differences in susceptibility to posttraumatic stress disorder. Behav Res Ther 38: 619-628.

23. Hager AD, Runtz MG (2012) Physical and psychological maltreatment in childhood and later health problems in women: an exploratory investigation of the roles of perceived stress and coping strategies. Child Abuse Negl. 36: 393-403.

24. Farley M, Golding JM, Minkoff JR (2002) Is a history of trauma associated with a reduced likelihood of cervical cancer screening? J Fam Pract 51: 827-831.

25. Farley M, Minkoff JR, Barkan H (2001) Breast cancer screening and trauma history. Women Health 34: 15-27.

26. Farley M, Patsalides BM (2001) Physical symptoms, posttraumatic stress disorder, and healthcare utilization of women with and without childhood physical and sexual abuse. Psychol Rep 89: 595-606

27. Leeners B, Stiller R, Block E, Görres G, Imthurn B, et al. (2007) Consequences of childhood sexual abuse experiences on dental care. J Psychosom Res 62 : 581-588.

28. Kronish IM, Edmondson D, Li Y, Cohen BE (2012) Post-traumatic stress disorder and medication adherence: results from the Mind Your Heart study. J Psychiatr Res 46: 1595-1599.

29. Pineles SL, Mostoufi SM, Ready CB, Street AE, Griffin MG, et al. (2011) Trauma reactivity, avoidant coping, and PTSD symptoms: A moderating relationship?. J Abnorm Psychol 120: 240-246.

30. Raja S, Hoersch M, Rajagopalan CF, Chang P (2014) Treating patients with traumatic life experiences: providing trauma-informed care. J Am Dent Assoc 145: $238-245$.

31. Substance Abuse and Mental Health Services Administration (2015) TraumaInformed Approach and Trauma-Specific Interventions. 
Citation: Raja S, Rajagopalan C, Hasnain M, Vadakumchery T, Kupershmidt A, et al. (2015) Trauma Informed Care in Medical Settings: A Pilot Study of Female Patient Perspectives on Coping, Screening and Fostering Resilience. J Womens Health, Issues Care 4:3.

32. Campbell $R$ (1998) The community response to rape: victims' experiences with the legal, medical, and mental health systems. Am J Community Psycho 26: $355-379$

33. McGregor K, Glover M, Gautam J, Jülich S (2010) Working sensitively with child sexual abuse survivors: what female child sexual abuse survivors want from health professionals. Women Health 50: 737-755

34. Madigan L, Gamble NC (1991) The second rape: Society's continued betrayal of the victim. Macmillan, New York.

35. Martin PY, Powell MR (1994) Accounting for the "second assault": Legal organizations' framing of rape victims. Law \& Social Inquiry 19: 853-890.

36. Campbell R, Raja S (1999) Secondary victimization of rape victims: insights from mental health professionals who treat survivors of violence. Violence Vict 14: 261-275

37. Friedman LS, Samet JH, Roberts MS, Hudlin M, Hans P (1992) Inquiry about victimization experiences: a survey of patient preferences and physician practices. Arch Intern Med 152: 1186-1190.
38. Schachter CL, Radomsky NA, Stalker CA, Teram E (2004) Women survivors of child sexual abuse. How can health professionals promote healing?. Can Fam Physician 50: 405-412.

39. Kvale S (1996) InterViews: an introduction to qualitative research interviewing. Sage, London.

40. Hancock B, Windridge K, Ockleford E (2007) An introduction to qualitative research. The National Institute for Health Research, USA.

41. Guba EG, Lincoln YS (1994) Handbook of Qualitative Research: Competing paradigms in qualitative Research. Sage, London.

42. Elo S, Kyngäs H (2008) The qualitative content analysis process. J Adv Nurs 62: $107-115$

43. National Association of State Mental Health Program Directors (2014) The National Center for Trauma Informed Care.

Author Affiliations

${ }^{1}$ Department of Pediatric Dentistry, College of Dentistry, University of Illinois at Chicago, USA

${ }^{2}$ College of Dental Medicine, Rutgers University, USA

${ }^{3}$ Department of Family Medicine, University of Illinois at Chicago, USA ${ }^{4}$ College of Liberal Arts and Sciences, University of Illinois at Chicago ${ }^{5}$ Office on Women's Health, Region V, U.S. Department of Health and Human Services, USA

Submit your next manuscript and get advantages of SciTechnol submissions

* 50 Journals

* 21 Day rapid review process

* 1000 Editorial team

* 2 Million readers

* Publication immediately after acceptance

- Quality and quick editorial, review processing

Submit your next manuscript at • www.scitechnol.com/submission 